Volume 8 - 2018 | n. 3

\title{
A Educação Pública e as Corporações: avanços e contradições em uma década de ampliação de investimento no Brasil
}

Theresa Adrião

Universidade Estadual de Campinas (UNICAMP), Campinas/SP - Brasil

Cassia Alessandra Domiciano

Universidade Metodista de São Paulo (UMESP), São Bernardo do Campo/SP - Brasil

\section{Resumo ${ }^{1}$}

Com base em pesquisas a fontes primárias e secundárias, o texto busca contribuir para a reflexão crítica sobre opções de políticas governamentais que implicaram na ampliação da simbiose entre governos e segmentos do setor privado corporativo ou a este associado. Para efeito desse intento, considera-se a destinação de recursos federais no período de 2002 a 2014, quando se ampliaram os gastos com a educação em relação ao PIB e o período de escolaridade obrigatória, paralelamente ao fortalecimento da "filantropia de risco" e de corporações na prestação de serviços aos sistemas públicos de ensino. Tratando-se de trabalho de natureza exploratória, os dados levantados apontam para a necessidade de pesquisas mais detalhadas sobre o repasse de fundos públicos para o setor privado.

Palavras-chave: Privatização. Fundos Públicos. Filantropia de Risco.

\section{Public Education and Corporations: advances and contradictions in one decade of expansion of investments in Brazil}

\section{Abstract}

This paper, an exploratory work, is based on primary and secondary sources and seeks to contribute to the critical reflection concerning governmental policies options that involved the expansion of the symbiosis between governments and the private sector corporate segments or associated with it. In order to do that, the allocation of federal resources in the period 20022014 is considered. In that period, the education expenditure (in comparison to the GDP ratio) and the mandatory period of education increased, alongside with the strengthening of "venture philanthropy" and corporations in the provision of services to education public systems. The results point to the need of more detailed research about the transference of public funds to the private sector.

Keywords: Privatization. Public Funds. Venture Philanthropy.

\footnotetext{
1 Trabalho desenvolvido com o apoio da Fundação de Amparo à Pesquisa do Estado de São Paulo (Fapesp).
} 
A Educação Pública e as Corporações

\section{Introdução}

A vitória do Partido dos Trabalhadores (PT) ${ }^{2}$ nas eleições presidenciais de 2002, com Luiz Inácio Lula da Silva, não poderia deixar de expressar e acirrar relações contraditórias entre as forças e os setores da sociedade brasileira que, de um lado, sustentaram a opção histórica por um partido dos trabalhadores e uma agenda de reformas comprometidas com a diminuição das históricas desigualdades observadas na sociedade brasileira e, de outro, os setores hegemônicos responsáveis por tais desigualdades, que tensionaram pela manutenção de seus privilégios. Reflexo dessas contradições expressou-se no compromisso com a "governabilidade" anunciado na "Carta aos Brasileiros"3.

Nesse documento, divulgado durante o processo eleitoral, o futuro presidente e o PT comprometiam-se a implantar um governo que resultasse de uma "ampla negociação nacional, que deve conduzir a uma autêntica aliança pelo país, a um novo contrato social, capaz de assegurar o crescimento com estabilidade". Afirmava ainda que a "premissa dessa transição será naturalmente o respeito aos contratos e obrigações do país", referindo-se à preocupação de investidores diante da posição do PT contra o pagamento da dívida externa, em defesa da reforma agrária etc. (SILVA, 2002)

Atualizando perspectivas de reforma na gestão pública iniciada com o Plano Diretor da Reforma do Aparelho do Estado, de 1995, e orientadas pelos pressupostos da Nova Gestão Pública (PERONI; ADRIÃO, 2005), o Partido dos Trabalhadores (PT), ao assumir os mandatos presidenciais no período de 2003 a 2010, aproximou-se da concepção de governança pública, sugerida por distintos organismos internacionais como alternativa às orientações neoliberais (KISSLER; HEIDEMANN, 2006) ou de cunho gerencial. A lógica da governança pública assimila o setor privado (lucrativo e não lucrativo) como agente e parceiro na elaboração das políticas públicas, dado o pressuposto de que a ação estatal ou governamental é insuficiente e, por vezes, refratária para apreciar e atender as demandas sociais.

Deriva dessa perspectiva de gestão pública o fato de várias Fundações e organizações correlatas buscarem esferas governamentais (ou serem por elas buscadas) com objetivo de oferecer seu "qualificado" apoio técnico. No caso brasileiro, as fundações configuram-se como organizações privadas sem fins lucrativos que, por força de lei, podem inclusive receber recursos públicos, sem que haja uma clara orientação para o accountability de sua ação e, em alguns casos, sem exigência de licitação.

Em 2014, segundo o Grupo de Institutos Fundações e Empresas (GIFE), o setor educacional respondeu por $85 \%$ dos investimentos dos 113 investidores privados então associados ao Grupo, os quais movimentaram, naquele ano, três bilhões de reais ${ }^{4}$. Segundo

2 O PT foi criado em 1980, por setores de esquerda oriundos de movimentos sociais diversos; setores de base da igreja católica, sindicalistas e distintas organizações de esquerda que romperam com as orientações dos tradicionais partidos comunistas. Para muitos autores e militantes, o PT se constituiu inicialmente como uma frente de esquerda, cujas orientações estiveram em disputa até o V Encontro Nacional de 1987.

3 Trata-se de Declaração pública assinada por Lula durante o processo eleitoral apresentando seus compromissos de governo.

4 Disponível em: <http://gife.org.br/investimento-social-corporativo-em-2014-foi-de-r-388-bilhoes/>. Acesso em: 21 abr. 2017. 
A Educação Pública e as Corporações

o documento, apenas $10 \%$ desse montante advinham de contratos/convênios com o setor público (FOUNDATION CENTER E GIFE, 2014).

Ainda assim, estudos identificam a atuação do setor privado junto aos sistemas públicos de ensino, tanto para a oferta da educação básica, financiada com recursos públicos por meio de parcerias público-privado, como o caso de Belo Horizonte (ADRIÃO; BEZERRA, 2013); de escolas em concessão ou conveniadas (BORGHI et al., 2012; ADRIÃO, 2014; DOMICIANO; 2016; FRANCO, 2015; PINTO; 2014), quanto para a venda de insumos curriculares por corporações e por segmentos a estes associados. Destaca-se a venda de livros didáticos, apostilas ou tecnologias de informação em geral; de sistemas de gestão envolvendo sistemáticas de avaliação de desempenho de estudantes e de escolas; de programas de qualificação de professores; de assessorias para a gestão etc. (ADRIÃO et al., 2009; 2012).

Este texto resulta de pesquisa exploratória cuja intenção é colaborar com a reflexão crítica a respeito das relações entre setores governamentais e o setor privado, especialmente os segmentos com finalidade lucrativa. Para tanto, o texto ancora-se em consultas a fontes primárias relativas a gastos em Manutenção e Desenvolvimento do Ensino (MDE) pelo governo federal; a dados de matrícula e a documentos institucionais disponíveis para consulta on line. Assenta-se ainda em diálogo com produções sobre a temática disponíveis em publicações especializadas.

Mais precisamente, intenta-se colaborar para a análise de um período no qual a educação básica foi elevada à prioridade governamental, 2004-2014, ao mesmo tempo em que a literatura indica a ampliação de formas de privatização.

\section{Notas sobre a organização e oferta da educação básica no Brasil em contexto de transformação da educação pública em "campo de Negócios"5}

O Brasil é um país federado, razão pela qual a responsabilidade pela oferta da educação, dentre outras responsabilidades estatais, encontra-se dividida entre as três esferas governamentais que o compõem: governo federal; governos estaduais (total de 26 estados) e governos municipais (5.570 no total), além da capital federal - Brasília - que possui status de estado. Desde 1988, considerando as Emendas Constitucionais posteriores e o contido no texto da Lei de Diretrizes e Bases da Educação Nacional (Lei nº 9394 de 1996), a divisão de responsabilidades para a oferta da educação básica é assimétrica, na medida em que delega aos municípios o dever de ofertar e manter a educação infantil e o ensino fundamental, neste caso, atuando conjuntamente com o governos estaduais, os quais devem garantir, prioritariamente, a oferta do Ensino Médio a todos com idade entre 15 e 17 anos.

A educação básica regular compreende o atendimento educacional de 0 a 17 anos, inclusive para deficientes. Além de sua oferta, os governos subnacionais devem ainda, por força de lei, garantir o atendimento aos jovens e adultos que não frequentaram a escola na idade "adequada".

O sentido atribuído à oferta da educação pública extrapola o do atendimento à demanda por meio de vagas na medida em que integra o conjunto das ações do Estado na direção da

5 Expressão adotada pela literatura anglo-saxã: Ball (2014) Hill (2003) e que se generalizou nas publicações críticas ou não sobre o tema. 
A Educação Pública e as Corporações

diminuição das desigualdades decorrentes de uma organização social e econômica cuja distribuição e controle dos bens produzidos é profundamente assimétrica (CASTRO, 2012)

Com Castro (2012, p. 1017), acredita-se que

[...] a geração de igualdades está relacionada à expansão da oferta de bens e serviços sociais, enquanto bens equalizadores providos pelo poder público, principalmente a escolarização e o acesso à saúde como elementos centrais na geração de habilidades e capacidades em indivíduos e/ou grupo social.

Nesses termos, a oferta educativa, como condição para a realização do direito à educação e, nesse sentido, como estratégia para o acesso a demais direitos (XIMENES, 2014), demanda insumos e condições adequados para o funcionamento das escolas.

Indaga-se se, no período selecionado para esta análise, tal oferta na qualidade e quantidade necessária foi ainda mais minimizada pela destinação de fundos públicos do governo federal para o setor privado.

\section{Contradições na e da ampliação de um direito: notas sobre o crescimento do mercado educacional subsidiado entre 2004 e 2014}

Entre 1988 e 2006, a obrigatoriedade de frequência à escola no Brasil compreendia a idade entre 7 a 14 anos, independentemente da etapa de escolaridade na qual se encontrasse o pequeno cidadão, condição que impunha o dever do Estado para com a oferta de vagas gratuitas a todos e a obrigação das famílias em matricular as crianças. Isto porque, ao se afirmar que o ensino é obrigatório, trabalha-se com uma dupla obrigatoriedade, que, segundo Oliveira (2007), refere-se ao dever do Estado em ofertar a vaga gratuita e aos responsáveis em garantir a matrícula e a frequência à escola.

Em 2005, a Lei Federal $n^{\circ} 11.114$ ampliou o ensino fundamental para nove anos e estendeu a matrícula obrigatória a partir dos seis anos; três anos depois, o Congresso Nacional Brasileiro aprovou, em 11 de novembro de 2009, a Emenda Constitucional (EC) $n^{\circ}$ 59 que deu nova redação aos incisos I e VII do art. 208 da CF, consolidando a obrigatoriedade do ensino para a população dos quatro aos dezessete anos na educação básica e, por consequência, ampliando os programas suplementares para todas as etapas da educação básica. As novas normas deveriam ser implementadas de modo progressivo até 2016 - nos termos do Plano Nacional de Educação, e com o apoio técnico e financeiro da União.

Por programas suplementares, as normas em vigor compreendem: material didático e escolar, transporte escolar, uniformes, alimentação. Ou seja, incorporam o conceito de gratuidade ativa (MELCHIOR, 1987), segundo o qual o efetivo direito à escola pressupõe mais que o não pagamento de mensalidades, já que envolve também condições efetivas de permanência a todos os estudantes. Se essa perspectiva é inegavelmente positiva e exige, para sua realização, condições mais abrangentes para efetivar o direito à educação, o fato de a oferta da educação básica estar a cargo de governos subnacionais, mais precisamente dos municípios, e o fato de o governo federal aportar, proporcionalmente, menos recursos do que arrecada para a educação básica geram distorções no "padrão ${ }^{6 "}$ da educação ofertada.

6 Estudo desenvolvido pela Campanha Nacional pelo Direito à Educação (2010) comparava o valor necessário para se garantir um padrão mínimo de qualidade, resultado de metodologia desenvolvida por Carreira e Pinto (2005), para as séries iniciais do ensino fundamental de meio período. Segundo a Campanha, o valor mínimo 
A Educação Pública e as Corporações

Dados relativos à matrícula total na educação básica regular, disponíveis nas Sinopses Estatísticas do Censo Escolar, indicam que no ano de 2005 cerca de 19 milhões e quatrocentas e cinquenta mil matrículas concentravam-se nas redes estaduais de ensino, enquanto os municípios respondiam por 17 milhões e 860 mil. Já em 2014, último ano do período em análise, aos estados coube o atendimento a 9 milhões e quatrocentos mil estudantes, enquanto os municípios assumiram a matrícula de 16 milhões e duzentos mil estudantes.

Para Pinto (2007, p. 881), embora os municípios possuam

[...] matrícula na educação básica maior que aquela apresentada pelos estados, sua receita líquida de impostos é bem inferior àquela obtida pelos estados (cerca de três quartos), o que demonstra uma situação de grande fragilidade do atual sistema de financiamento.

Em síntese, mais de $50 \%$ das matrículas da educação básica estão sob responsabilidade dos municípios, esfera menos aparelhada técnica e financeiramente para essa tarefa, mas que vivenciam, mais diretamente, as pressões da sociedade por assegurar a efetivação de direitos à educação. Cumpre lembrar que os municípios, como os demais entes federados, desde 2001, encontram-se subordinados à Lei de Responsabilidade Fiscal $(\mathrm{LRF})^{7}$, a qual, ao fixar os gastos governamentais com pessoal em no máximo $60 \%$, induz à transferência de parte considerável das atividades educacionais para o setor privado (ADRIÃO et al., 2009).

Esses condicionantes explicam, em parte, a generalização de programas e políticas que se apoiam no setor privado, lucrativo ou não lucrativo, como "solução" para a oferta e gestão educacional em âmbito subnacional (ADRIÃO et. al. 2009).

São a natureza e a abrangência dos mecanismos de "simbiose" entre os setores privados e órgãos públicos que indicam a amplitude dos processos de privatização da educação pública, esta entendida como o conjunto de processos que têm direcionado a educação básica pública brasileira para o campo e sob o interesse do setor privado corporativo ou a este associado (ADRIÃO, 2017a).

Dois exemplos de fundações, vinculadas ao mundo corporativo e alçadas à interlocutores privilegiados dos governos, auxiliam na compreensão desse processo. $O$ primeiro refere-se à atuação do Instituto Ayrton Senna - IAS, que vem operando diretamente junto a estados e municípios por meio da implantação de "tecnologias educacionais" adquiridas com recursos públicos (ADRIÃO; PERONI, 2013). Em 2014, o IAS demandou da Agência de regulação e financiamento do ensino superior no Brasil (CAPES), autarquia do governo federal, o lançamento de um edital ( $\left.n^{\circ} 44 / 2014\right)$ para desenvolvimento de pesquisa sobre medição de "habilidades socioemocionais", com subsídio público no valor aproximado de U\$ 242 mil.

Entretanto, é o segundo exemplo o que merece destaque nesta reflexão: a Fundação Lemann, cujo fundador, Jorge Paulo Lemann, é também um dos principais investidores do

deveria ser de aproximadamente U\$ 775 aluno/ano, sem considerar as despesas com alimentação escolar. Entretanto, no mesmo ano, o FUNDEB previa U\$ 485. A diferença entre o realmente praticado e o estimado como necessário era ainda mais evidente quando se comparava os valores para o atendimento em creches (0 a 3 anos): U\$ 2.094 contra os U\$ 534 previstos pelo Fundeb (CAMPANHA..., 2010).

7 Lei Complementar $n^{\circ} 101$, de 4 de maio de 2000. 
Grupo Eleva Educação, holding de educação, criado em 2013, que atua tanto na oferta direta de educação privada, por meio de escolas próprias, quanto no desenvolvimento de um sistema privado de ensino adotado por cerca de 80 escolas. Por sua vez, parte do investimento necessário à criação dessa holding, veio do Gera, empresa de investimento de risco, do mesmo grupo, com foco em empreendimentos educacionais (ADRIÃO, 2017a).

A lógica do "Grupo Lemann", ilustrada na Figura 1, é a versão brasileira das chamadas venture philanthropic entities, modelo de investimento estimulado pela Organização para Cooperação e Desenvolvimento Econômico (OCDE) que tem acelerado a transformação dos sistemas públicos de ensino em mercados. Trata-se de fundações ou organizações similares a estas, vinculadas ao setor empresarial, que oferecem seus préstimos a diferentes governos, como parte de suas estratégias para ampliação e o desenvolvimento de novos produtos e serviços os quais, por sua vez, alavancarão empresas emergentes (ADRIÃO, 2015; 2017a). Tais setores investem na educação para crianças pobres ou minorias, financiam programas $e$ redes públicas, utilizam a linguagem e a lógica do mercado e esperam retornos agressivos para seus investimentos (ROBERTSON; VERGER, 2012).

\section{Figura 1 - llustração da dinâmica de funcionamento de parte do segmento educacional do Grupo Lemann}

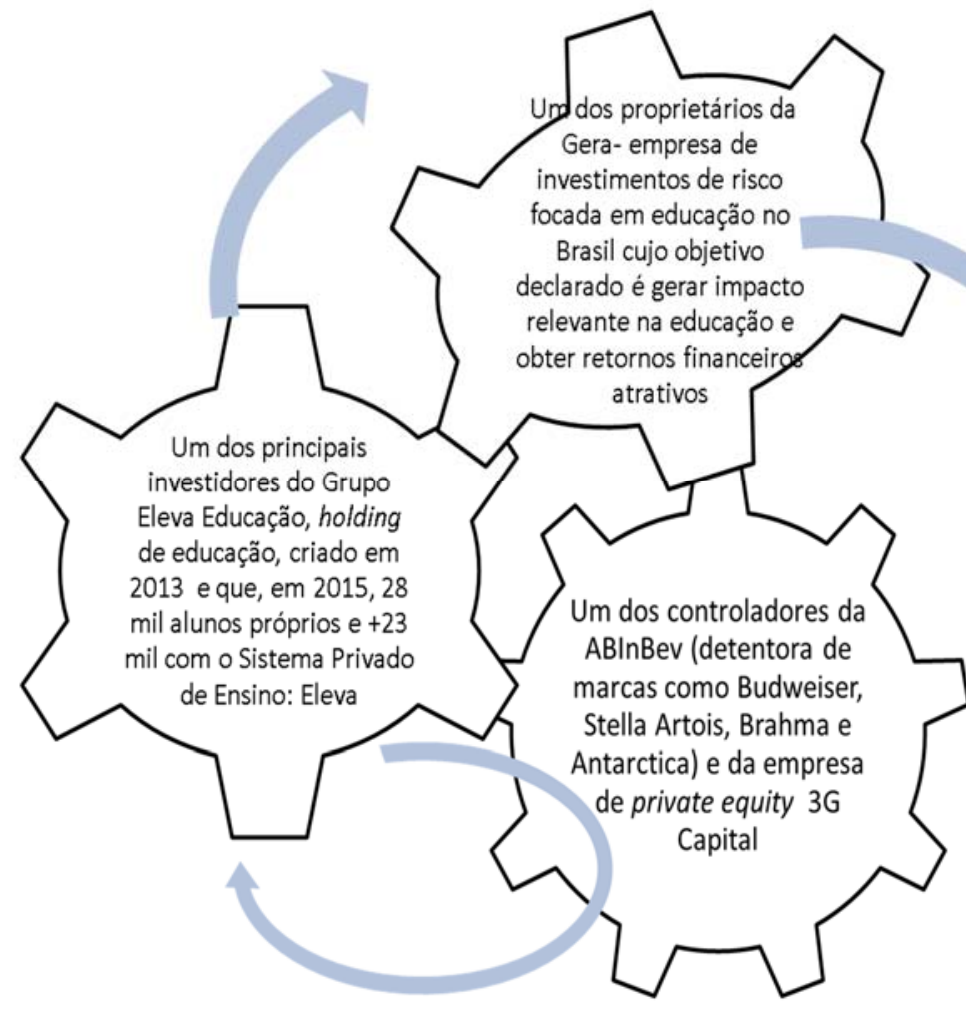

Fonte: Elaboração das autoras com base em Adrião (2017) e informações disponíveis em: <http://www.geraventure.com.br/>. Acesso em: 18 abr. 2017.

Nota: Growth equity é um tipo de investimento privado dirigido à expansão de novos mercados e Start ups e Private equity.

Em âmbito global, desde 2012, a OCDE instituiu uma rede global, vinculada ao Centro de Desenvolvimento da própria organização, constituída por um pequeno grupo de fundações cujo objetivo é o estímulo a inovações desenvolvidas por filantropos empresariais para que 
A Educação Pública e as Corporações

estas se constituam em alternativas diante da diminuição dos fundos públicos para o setor social (ADRIÃO, 2017a).

Paralelamente à presença da venture philantropy e acompanhando tendência mundial (BALL, 2014; HILL, 2003) verificou-se, no início deste século, o crescimento da atuação de grandes grupos privados, como provedoras de insumos curriculares a redes públicas de ensino. De início, o principal produto comercializado foi identificado como Sistemas Privados de Ensino (SPE), "cesta" de insumos curriculares, processos de gestão e de avaliação educacional que variam segundo a capacidade orçamentária do governo contratante (ADRIÃO et al. 2009; ADRIÃO et al. 2015; 2016; HYPÓLITO; GANDIN, 2013). No final da década, os produtos associavam-se a plataformas de acesso a dados e conteúdos digitais, desenvolvidos principalmente por start ups, financiadas pela venture philantropy.

Em linhas gerais, o percurso dos grupos privados apresentou relativa similaridade: originários da educação privada, ampliaram sua inserção primeiro incorporando estabelecimentos educacionais concorrentes de menor porte; depois, substituindo a incorporação física de escolas privadas menores ou deficitárias pela oferta de um conjunto de serviços e produtos padronizados e organizados, os SPE, na forma de franquias de suas "marcas" para estabelecimentos privados e, por fim, o terceiro ciclo caracterizou-se pela incorporação de redes públicas de ensino às "carteiras" de clientes, para o que desenvolveram logísticas; produtos e serviços distintos das franquias privadas e, em geral, de menor qualidade (ADRIÃO et al., 2012; GARCIA et al., 2012)

A partir de 2010, uma quarta fase se delineia nesse segmento do mercado educacional brasileiro com o ingresso de grandes grupos editorias, como o Grupo Abril (que adquire empresas de menor porte) e a Editora Moderna/Santillana, com composição de capital internacional. Na sequência, alguns grupos abrem seus capitais e passam a ser geridos em todo ou em parte por fundos de investimentos. Exemplos nessa direção encontram-se nas dinâmicas assumidas pelo Grupo COC, parte do qual após abrir seu capital foi adquirido pela inglesa Pearson ou no ocorrido ao Grupo Abril Educação, adquirido pela Tarpon em negociação que envolveu US\$ 436,5 milhões (ADRIÃO et al., 2016; ADRIÃO, 2017a; GALZERANO, 2016).

Esse movimento, ocorrido entre os anos de 2003 a 2014, associa-se a um quadro de "liberalização" e relativo estímulo à atuação de fortes segmentos privados no campo da educação básica pública estimulado, em parte, pela destinação de fundos públicos para o setor e pela criação de um marco regulatório que favorece a transferência de atividades estatais para o setor privado (DI PIETRO, 2005). Trabalho anterior indicava, por exemplo, que o governo do Estado de Pernambuco - o primeiro estado brasileiro a transferir a gestão de escolas públicas para o setor privado, nomeadamente para o Instituto de Corresponsabilidade Educacional (ICE) - destinou, em 2014, 0,61\% de sua receita total da Educação para o setor privado; enquanto que, para os 185 municípios, repassou apenas $2,33 \%$ da receita (ADRIÃO; GARCIA; AZEVEDO, 2016).

Também em âmbito federal, o volume repassado ao setor privado foi evidente, conforme ilustra a Tabela 1, ao tomar como ano de comparação o último exercício do mandato de Fernando Henrique Cardoso (2002) e comparar com os percentuais gastos nos últimos anos de cada mandato de Luiz Inácio Lula da Silva (2006 e 2010) e de Dilma Rousseff (2014). 
Tabela 1 - Gasto total e percentual direcionado ao setor privado (categorias escolhidas) das despesas do Governo Federal com Manutenção e Desenvolvimento do Ensino - MDE - Anos selecionados - Valores nominais em milhões

\begin{tabular}{c|c|c|c|c|c}
\hline $\begin{array}{c}\text { Ano de } \\
\text { exercício }\end{array}$ & $\begin{array}{c}\text { Gasto total } \\
\text { em MDE* }\end{array}$ & $\begin{array}{c}\text { Gasto } \\
\text { direcionado } \\
\text { ao setor } \\
\text { privado** }\end{array}$ & $\begin{array}{c}\text { Gasto } \\
\text { direcionado } \\
\text { aos } \\
\text { municípios }\end{array}$ & $\begin{array}{c}\text { Percentual do } \\
\text { gasto total em } \\
\text { MDE } \\
\text { destinado ao } \\
\text { setor privado }\end{array}$ & $\begin{array}{c}\text { Percentual do } \\
\text { gasto total em } \\
\text { MDE } \\
\text { destinado aos } \\
\text { municípios }\end{array}$ \\
\hline 2002 & 10.797 .567 & 2.906 .968 & 1.754 .501 & $26,92 \%$ & $16,25 \%$ \\
2006 & 14.801 .195 & 3.213 .959 & 2.345 .004 & $21,71 \%$ & $15,84 \%$ \\
2010 & 14.824 .678 & 2.686 .112 & 627.689 & $18,12 \%$ & $4,23 \%$ \\
\hline 2014 & 35.639 .626 & 8.514 .455 & 5.508 .955 & $23,89 \%$ & $15,46 \%$ \\
\hline
\end{tabular}

Fonte: Relatório Resumido Da Execução Orçamentária, anos selecionados. Disponíveis em:

$<$ http://portal.inep.gov.br/demonstrativo-de-mde> e <http://www.tesouro.fazenda.gov.br/modelo-artigo-contabilidade-publica/lasset_publisher/o9mRBdHXTRjK/content/relatorio-resumido-de-execucao-orcamentaria>. Acessos em: março e outubro de 2017. Valores nominais atualizados para dezembro de 2017, pelo Índice Nacional de Preços ao Consumidor (INPC-IBGE).

Obs. *Gasto exclui vencimentos e obrigações patronais; **Valores referentes à soma das despesas com serviços de terceiros pessoa física; serviços de terceiros pessoa jurídica; transferências às instituições privadas sem fins lucrativos e consultoria ${ }^{8}$.

Considerando-se os recursos de Manutenção e Desenvolvimento do Ensino (MDE) para os anos selecionados e excluindo-se os gastos com vencimentos e obrigações patronais, lembrando que estes compõem a maior parte das despesas, tem-se que, no mínimo, $18 \%$ das despesas destinaram-se ao setor privado, conforme indicado na terceira coluna da Tabela 1. No cálculo levou-se em conta as categorias econômicas transferências às instituições privadas sem fins lucrativos; serviços de terceiros - pessoa física; serviços de terceiros - pessoa jurídica e serviços de consultoria, pelo fato de permitirem identificar, de forma mais evidente, a destinação de fundos públicos ao setor privado.

Se é possível observar pela Tabela 1, o crescimento do investimento em educação, principalmente entre 2010 e 2014 (140\%), é certo também que os recursos de MDE destinados ao setor privado acompanharam tal incremento - triplicaram entre 2010 e 2014.

Cumpre dizer ainda que, nos demonstrativos de despesas dos Orçamentos Fiscal e da Seguridade Social da União para os anos selecionados e, excetuando-se os repasses constitucionalmente definidos, os recursos de MDE do Governo Federal para os municípios estiveram bem aquém dos destinados ao setor privado, uma vez que somados os valores associados à despesa liquidada identificada pela categoria econômica 3.33.40.00, que representa a modalidade de aplicação de recursos de transferências financeiras aos

8 De acordo com Manual para preenchimento do SIOPE, os itens selecionados corresponderam às despesas nas seguintes categorias econômicas: 3.33.90.36 - SERVIÇOS DE TERCEIROS - PESSOA FÍSICA- "Referente despesas decorrentes de serviços prestados por pessoa física pagos diretamente a esta e não enquadrados nos elementos de despesa específicos, tais como: remuneração de serviços de natureza eventual, prestado por pessoa física sem vínculo empregatício; estagiários, monitores diretamente contratados e outras despesas pagas diretamente à pessoa física. 3.33.90.39 - SERVIÇOS DE TERCEIROS - PESSOA JURÍDICA - despesas com prestação de serviços por pessoas jurídicas para órgãos públicos, tais como: assinaturas de jornais e periódicos; energia elétrica e gás; serviços de comunicação; fretes e carretos; locação de imóveis (inclusive despesas de condomínio e tributos à conta do locatário quando previstos no contrato de locação); locação de equipamentos e material permanente; seguro geral (exceto o decorrente de obrigação patronal); serviços de asseio e higiene (inclusive taxas de água e esgoto, tarifas de lixo); serviços de divulgação, impressão, encadernação e emolduramento; serviços funerários; despesas com congressos, simpósio, conferências ou exposições; despesas miúdas de pronto pagamento; vale transporte; vale refeição; auxílio creche. 3.3.33.50 TRANSFERÊNCIAS A INSTITUIÇÕES PRIVADAS SEM FINS LUCRATIVOS - representa o somatório dos valores das despesas realizadas mediante transferência de recursos financeiros a entidades sem fins lucrativos que não tenham vínculo com a administração pública. 3.33.91.35 - SERVIÇOS DE CONSULTORIA - despesas decorrentes de contratos com pessoas físicas ou jurídicas, prestadoras de serviços nas áreas de consultorias técnicas ou auditorias financeiras ou jurídicas ou assemelhadas (BRASIL; MEC, 2016, p. 56-57). 
A Educação Pública e as Corporações

municípios, encontramos os valores expressos na quarta coluna da Tabela 1, os quais, no último ano selecionado (2014), ficaram $8,43 \%$ abaixo dos montantes direcionados ao setor privado (BRASIL, 2014; 2010, 2006 e 2002).

A respeito da destinação de recursos às demais esferas do governo, chamadas de transferências voluntárias ${ }^{9}$, embora existam trabalhos (D'ABADIA, 2015; MOUTINHO, 2016) que mapearam o volume desses recursos às esferas subnacionais, não há identificação, nessas investigações, de valores relacionados à Manutenção e Desenvolvimento do Ensino (MDE).

Relatório publicado pelo Tribunal de Contas da União, o qual teve como objetivo examinar a política de alocação de recursos federais aos municípios por meio de transferências voluntárias no período de 1996 a 2011 (BRASIL; TCU, 2016), confirma a reduzida participação financeira do Governo Federal para com o ente federado mais frágil da esfera federativa brasileira.

Os resultados do levantamento realizado pelo TCU, mostraram que o Governo Federal repassou aos municípios brasileiros um montante de $\mathrm{R} \$ 571,7$ bilhões no intervalo de 1996 a 2011 , sendo que apenas $3,8 \%$ representavam as transferências voluntárias. O documento destacou também que a metade desses recursos estava vinculada a emendas parlamentares, ou seja, não necessariamente ligadas a prioridades governamentais.

Para José de Assunção Moutinho (2016), o fato de um expressivo percentual das transferências estarem vinculadas às emendas parlamentares, pode expressar mais a submissão deste à força política desses entes do que aos "critérios de redução das desigualdades inter-regionais e de atendimento das necessidades das populações locais" (MOUTINHO, 2016, p. 163).

Quanto à alocação dos recursos federais ao setor privado, os dados presentes na Tabela 1 confirmam tendência identificada para os gastos em âmbito estadual (ADRIÃO et al., 2017b), lembrando que, no período, ampliou-se a proporção do gasto público total em educação básica em relação ao PIB, como indicado na Tabela 2, organizada segundo as distintas etapas da educação básica. Os dados correspondem ao período entre o primeiro ano do Mandato de Luiz Inácio Lula da Silva e o último ano do primeiro mandato de Dilma Rousseff. Esclarece-se que o investimento público total

[...] representa a soma de todos os recursos aplicados pelo setor público (União, Estados e municípios) em educação. Esse montante de recursos inclui, também, a estimativa para a aposentadoria futura do pessoal atualmente ativo no setor educacional, que não está contemplado no Investimento Direto (MACIEL, 2009, p. 10).

9 As transferências voluntárias encontram-se definidas no Art. 25, da Lei Complementar $n^{\circ} 101$, de 4 de maio de 2000 (LRF) "[...] entende-se por transferência voluntária a entrega de recursos correntes ou de capital a outro ente da Federação, a título de cooperação, auxílio ou assistência financeira, que não decorra de determinação constitucional, legal, ou os destinados ao Sistema Único de Saúde". 
A Educacão Pública e as Corporações

Tabela 2 - Estimativa do Percentual do Investimento Público Total em Educação Básica em Relação ao Produto Interno Bruto (PIB), por Nível de Ensino - Brasil 2003-2014

\begin{tabular}{|c|c|c|c|c|c|c|}
\hline \multirow{4}{*}{ Ano } & \multicolumn{6}{|c|}{$\begin{array}{l}\text { Percentual do Investimento Público Total em relação ao PIB } \\
(\%)\end{array}$} \\
\hline & \multirow{3}{*}{$\begin{array}{c}\text { Todos os } \\
\text { Níveis de } \\
\text { Ensino }\end{array}$} & \multicolumn{5}{|c|}{ Níveis de Ensino } \\
\hline & & \multirow[b]{2}{*}{$\begin{array}{l}\text { Educação } \\
\text { Básica }\end{array}$} & \multirow[b]{2}{*}{$\begin{array}{l}\text { Educação } \\
\text { Infantil }\end{array}$} & \multicolumn{2}{|c|}{ Ensino Fundamental } & \multirow[b]{2}{*}{$\begin{array}{l}\text { Ensino } \\
\text { Médio }\end{array}$} \\
\hline & & & & $\begin{array}{c}\text { De } 1^{\mathrm{a}} \text { a } 4^{\mathrm{a}} \\
\text { Séries ou } \\
\text { Anos } \\
\text { Iniciais }\end{array}$ & $\begin{array}{c}\text { De } 5^{a} \text { a } 8^{a} \\
\text { Séries ou } \\
\text { Anos } \\
\text { Finais }\end{array}$ & \\
\hline 2003 & 4,6 & 3,7 & 0,4 & 1,5 & 1,2 & 0,6 \\
\hline 2004 & 4,5 & 3,6 & 0,4 & 1,5 & 1,2 & 0,5 \\
\hline 2005 & 4,5 & 3,6 & 0,4 & 1,5 & 1,2 & 0,5 \\
\hline 2006 & 4,9 & 4,1 & 0,4 & 1,6 & 1,5 & 0,6 \\
\hline 2007 & 5,1 & 4,2 & 0,4 & 1,6 & 1,5 & 0,7 \\
\hline 2008 & 5,3 & 4,4 & 0,4 & 1,7 & 1,6 & 0,7 \\
\hline 2009 & 5,6 & 4,7 & 0,4 & 1,8 & 1,7 & 0,8 \\
\hline 2010 & 5,6 & 4,7 & 0,4 & 1,8 & 1,7 & 0,8 \\
\hline 2011 & 5,8 & 4,8 & 0,5 & 1,7 & 1,6 & 1,0 \\
\hline 2012 & 5,9 & 4,9 & 0,6 & 1,7 & 1,5 & 1,1 \\
\hline 2013 & 6,0 & 4,9 & 0,6 & 1,6 & 1,5 & 1,1 \\
\hline 2014 & 6,0 & 4,9 & 0,7 & 1,6 & 1,5 & 1,1 \\
\hline
\end{tabular}

Fonte: Inep/MEC - Tabela elaborada pela Deed/Inep. Disponível em:

<http://download.inep.gov.br/informacoes_estatisticas/investimentos_publicos_em_educacao/indicadores _financeiros_educacionais/investimento_pib_total.xlsx>. Acesso em: $0 \overline{7}$ dez. 2017.

Apesar de chegar-se a $6 \%$ do PIB em 2014, segundo o Relatório da OCDE (Organização para a Cooperação e Desenvolvimento Econômico) Education at a Glance: OECD Indicators (2014), o gasto anual por aluno ${ }^{10}$ para 2012 nos anos iniciais do ensino fundamental no Brasil correspondeu a 3.095 USD, enquanto a média dos países da OCDE ficou em 8.247 USD. Diferença equivalente encontra-se na comparação para os anos finais do ensino fundamental e ensino médio: 3.020 USD e 9.518 USD, respectivamente. Essa desigualdade é ainda agravada se considerarmos que parte desses recursos é destinada à ampliação dos lucros de setores que encaram a educação pública como mercado para seus negócios.

A partir dos dados publicados por Mendes (2015), reproduzidos na Tabela 3 a seguir, observa-se a proporção de gastos do governo federal com a educação básica e os ensinos superior e profissional, neste caso, integrados por gastos com o Prouni e o Pronatec.

Tabela 3 - Despesa do Governo Federal em Educação: programas voltados para ensino superior e profissional vs. programas voltados para educação básica: participação \% no total

\begin{tabular}{l|c|c} 
& $\mathbf{2 0 0 4}$ & $\mathbf{2 0 1 4}$ \\
\hline Educação Superior e Profissional & $55 \%$ & $63 \%$ \\
Educação Básica & $45 \%$ & $37 \%$ \\
\hline
\end{tabular}

Fonte: Mendes (2015, p. 10). Nota: exclui os itens "Pessoal e encargos sociais",

"Exames, avaliações, estatísticas e censos" e "Outros".

Se olharmos mais de perto a destinação dos recursos da União, identificamos no período aqui em destaque dois movimentos: a concentração dos recursos federais no ensino

10 Valores em USD - dólares dos Estados Unidos e usando o Purchasing Power Parity (PPP) - Paridade do Poder de Compra. 
A Educação Pública e as Corporações

técnico profissional e no ensino superior (Tabela 3) e destinação de fundos públicos para instituições privadas (Tabela 1).

Reforça a amplitude do gasto da União com instituições privadas, o estudo desenvolvido por Mendes (2015), segundo o qual, as despesas do Governo Federal com o Fundo de Financiamento Estudantil (FIES), em 2014 só perdeu em volume para os gastos com pessoal e para os gastos decorrentes da complementação da União para o Fundef/Fundeb: respectivamente 0,20 e 0,25 do PIB.

Também na comparação de gastos tributários decorrentes de isenções e desonerações tributárias autorizadas pela União, o autor identifica, direta ou indiretamente, o crescimento da subvenção a instituições privadas, seja por meio do desconto no Imposto de Renda de despesas com educação privada (aumento de 185\% entre 2004/2014), seja por meio da isenção fiscal a instituições privadas sem fins lucrativos (aumento de $525 \%$ no período de 2004 a 2014) (MENDES, 2015).

Dados publicados no Portal da Transparência do Governo Federal permitem endossar a afirmação feita por Mendes (2015) e complementar os dados relativos ao protagonismo de certas corporações na prestação de serviços aos sistemas públicos de ensino, uma vez que, ao verificar o gasto empreendido pelo FNDE, encontramos no último ano da série analisada (2014) o total de $R \$ 22$ bilhões ${ }^{11}$ vinculado a este órgão. Deste total, $R \$ 17$ bilhões corresponderam ao gasto com o FIES e R $\$ 5$ bilhões com despesas relacionadas a outros gastos e programas administrados pelo Fundo. Ao verificar os $\mathrm{R} \$ 5$ bilhões de forma desagregada, chegamos a 49,30\% (R $\$ 2,5$ bilhões) deste total destinados a auxílio financeiros a estudantes (3.3.90.18) e material de distribuição gratuita (3.3.90.32), e, quanto ao destino do dinheiro público nesses elementos de despesa (18 e 32), encontramos nomes já bastante conhecidos no cenário nacional, como Anhanguera Educacional, Estácio de Sá, Faculdades Maurício de Nassau, Uninove, Editora Abril, Ática, Moderna/Santilhana, Saraiva, Positivo, Scipione, Pearson, dentre outros.

Cabe considerar, ainda, que o percentual de quase $50 \%$ citado corresponde à somatória de apenas dois elementos de despesas que concentraram o maior volume de gasto do FNDE em 2014. Não seria surpresa, ao se deter com mais profundidade nos demais elementos de despesas, encontrar percentual maior.

\section{Considerações Finais}

O primeiro aspecto a considerar refere-se à desproporção entre capacidade tributária dos municípios e alguns Estados e as demandas pela efetivação dos direitos à educação, quando considerado o papel reservado à União. Apesar de a Constituição Federal de 1988 ter atribuído aos municípios a figura de ente federado, condição que reserva autonomia política e administrativa aos governos locais, sua subordinação técnica e financeira, para não falar da histórica subordinação política, aos poderes supralocais continuou inegável. A mesma situação pode ser atribuída aos Estados mais pobres em relação ao governo federal. Estudos de Rezende et al. (2008); Pinto, Amaral e Abrahão (2011); Sena, (2011); Cruz (2009) e Araújo (2014) salientam essas distorções correlacionando-as às desigualdades e assimetrias de

11 Os valores encontram-se atualizados com base no Índice Nacional de Preços ao Consumidor (INPC), para dezembro de 2017. 
A Educação Pública e as Corporações

nosso modelo tributário e à baixa participação do governo federal no financiamento da educação básica.

Soma-se a essas desigualdades um volume considerável de recursos da União para MDE destinados a setores privados. Mesmo sem o detalhamento dos itens de despesa efetivamente envolvidos em cada caso, dado o escopo deste trabalho, e mesmo considerando a diversidade de itens que podem ser alocados na categoria serviços de terceiros - pessoa jurídica, é certo afirmar que o destino dos recursos de MDE do governo federal foi em grande medida para o setor privado, com destaque para ano de 2006, cuja análise demanda estudos posteriores. $\mathrm{O}$ ano de 2014 também é emblemático, principalmente quando, juntamente com Mendes (2015), se verifica o montante de recursos do FNDE destinado ao FIES e a diferentes atores privados.

As opções adotadas pelo Governo Federal aqui selecionadas apenas contornaram esse problema, de sorte que o que se observou foi o aprofundamento de processos de privatização por meio da ampliação dos convênios e da oferta privada com subsídio público, conforme constatado nos dados apresentados.

Além disso, a subordinação da educação (e também da saúde) aos dispositivos da Lei de Responsabilidade Fiscal precisa ser revista, sob pena de aprofundar-se a desigualdade da oferta educativa: pela terceirização das atividades pedagógicas; precarização dos contratos ou transferência da oferta educacional ao setor privado, aos moldes dos conveniamentos, cujos profissionais não se encontram amparados pelos estatutos dos profissionais do magistério. A precarização dos vínculos trabalhistas e das condições de trabalho acentua-se com as políticas recentes de "austeridade fiscal", as quais efetivamente implantam as orientações neoliberais.

Em nome de um "compromisso" com o direito à educação, corporações, fundações e institutos vinculados a interesses empresarias (FREITAS, 2014), de maneira articulada, atuaram na definição das políticas educacionais do governo federal e transformam, paulatinamente, o direito à educação em um campo de negócios (HILL, 2003; KLEES, 2012).

Por último, frisa-se que a implantação de um padrão mínimo de qualidade de ensino, como previsto no PNE $^{12}$ (2014-2024) por meio do CAQi (Custo Aluno-Qualidade Inicial), aliada à manutenção da vinculação mínima de recursos e à sua ampliação para o Fundeb, constituem-se em instrumentos fundamentais para a ampliação do direito à educação.

Entretanto, em tempos de ajustes fiscais, diminuição da ação estatal e do controle social dos gastos públicos, certamente se aprofundarão as distorções e desigualdades existentes quanto mais os provedores daquele direito estiverem subordinados a interesses privados corporativos, como temos acompanhado.

Lembremos que, segundo a Lei de Diretrizes e Base da Educação Nacional, de 1996, a oferta educacional pode ser pública (estatal) ou privada. No primeiro caso, dá-se em escolas ou universidades municipais, estaduais ou federais que devem ser gratuitas. As escolas privadas podem ter ou não finalidade lucrativa, podendo o poder público financiar a frequência escolar por meio de subsídios na forma de bolsas de estudos, de linhas de crédito para os estudantes ou outras formas de subvenções. Mas também pode o poder público financiar as escolas privadas de forma indireta por meio de isenções de tributos, como quando se autoriza

12 Lei 13.005, de 25 de junho de 2014. 
A Educacão Pública e as Corporações

o abatimento nos impostos de renda de pessoas físicas dos gastos com o ensino privado, ou quando se isenta do pagamento de impostos as próprias instituições, ambos os casos reportados por Mendes (2015).

Em outras palavras, caso não se comece a construir um sistema permanente de financiamento à educação que vá além do Fundeb, em 2020 as redes municipais de, pelo menos, metade dos estados brasileiros entrarão em colapso financeiro.

\section{Referências}

ADRIÃO, Theresa et al. Uma modalidade peculiar de privatização da educação pública: a aquisição de "sistemas de ensino" por municípios paulistas. Educação e Sociedade, Campinas, v. 30, n. 108, p. 799-818, 2009. Disponível em: <http://www.scielo.br/scielo.php? script=sci_arttext\&pid=S0101-73302009000300009\&Ing=en\&nrm=iso>. Acesso em: 21 abr. 2017.

ADRIÃO, Theresa et.al. As parcerias entre prefeituras paulistas e o setor privado na política educacional: expressão de simbiose?. Educação e Sociedade, Campinas, v. 33, n. 119, p. 533-549, abr./jun. 2012. Disponível em: <http://www.scielo.br/scielo.php?script=sci_ arttext\&pid=S0101-73302012000200011\&lng=en\&nrm=iso>. Acesso em: 08 dez. 2017.

ADRIÃO, Theresa et al. Sistemas de ensino privados na educação pública brasileira: consequências da mercantilização para o direito à educação. Relatório de Pesquisa - 2015. 144p. Disponível em: <http://flacso.org.br/files/2016/04/Peri-Sistemas-de-Ensino-Privado-naEduca\%C3\%A7\%C3\%A3o-P\%C3\%BAblica-Brasileira-ok.pdf>. Acesso em: 05 dez. 2017.

ADRIÃO, Theresa et al. Grupos empresariais na educação básica pública brasileira: limites à efetivação do direito à educação. Educação e Sociedade, Campinas, v. 37, p. 113-131, 2016. Disponível em: <http://www.scielo.br/scielo.php?script=sci_arttext\&pid=S0101-7330201600 0100113>. Acesso em: 05 dez. 2017.

ADRIÃO, Theresa; PERONI, Vera (Org.). Gestão Municipal da Educação e as parcerias com o Instituto Ayrton Senna. Recife: FANAPE-ANPAE, 2013.

ADRIÃO, Theresa; BEZERRA, Egle Pessoa. O setor não lucrativo na gestão da educação pública: corresponsabilidade ou debilidade. Currículo sem Fronteiras, Porto Alegre; Lisboa, v. 13 , n. 2, p. 256-268, maio/ago. 2013.

ADRIÃO, Theresa; GARCIA, Teise; AZEVEDO, J. P. Educação Obrigatória no Brasil: tendências de privatização e limites ao direito à educação. Belfast, 2016. 15p. (mimeo).

ADRIÃO, Theresa. A Privatização da Educação Básica no Brasil: considerações sobre a incidência de corporações na gestão da educação pública. In: PINTO, José Marcelino; ARAUJO, Luiz (Org.). Público X Privado em tempos de golpe. São Paulo: Fundação Lauro Campos/ Fineduca, 2017a.

ADRIÃO, Theresa. Financiamento no Ensino Médio no Brasil: estudo sobre os gastos públicos na região Sudeste. Políticas Educativas, Santa Maria, v. 10, n. 2, p. 17-36, 2017b.

ARAÚJO, Raimundo Luiz Silva. Limites e possibilidades da redução das desigualdades territoriais por meio do financiamento da educação básica. 2014. Tese (Doutorado em Educação) - Faculdade de Educação, Universidade de São Paulo, São Paulo, 2014. 
A Educação Pública e as Corporações

BALL, Stephen. Educação global S.A. Novas redes políticas e o imaginário neoliberal. Ponta Grossa: Editora UEPG, 2014.

BORGHI, Raquel Fontes et al. A Oferta Educacional Da Educação Infantil: arranjos institucionais entre o público e o privado. Relatório de Pesquisa, CNPQ, 2012.

BRASIL. Constituição da República Federativa de 1988. Diário Oficial da União, Brasília, DF, 1988

BRASIL. Lei $n^{\circ}$ 9.394, de 20 de dezembro de 1996. Estabelece as diretrizes e bases da educação nacional. Diário Oficial da União, Brasília, 1996.

BRASIL. Plano de Desenvolvimento em Educação: razões, princípios e programas. Brasília: MEC: 2007.

BRASIL. Tribunal de Contas da União (TCU). Alocação de recursos federais aos municípios mediante transferências voluntárias. Ciência da deliberação a diversos órgãos. Relatório do levantamento de Auditoria. Brasília: Secretaria Executiva do Ministério do Planejamento, Orçamento e Gestão, 2016. 55 f. Disponível em: <http://portal.tcu.gov.br/lumis/portal/file/ fileDownload.jsp?fileld=8A8182A1536CDFB80153818CD6B578DA\&inline=1>. Acesso em: 05 dez. 2017.

BRASIL. Ministério da Educação (MEC). Demonstrativo de MDE. Brasília: INEP, 2016.

BRASIL. Tesouro Nacional. SIAF. Receitas e Despesas da União com Manutenção e Desenvolvimento do Ensino - 2000 a 2017. Brasília, 2017. Disponível em: <http://www.tesouro.fazenda.gov.br/series-historicas>. Acesso em: 01 fev. 2017.

CAMPANHA NACIONAL PELO DIREITO À EDUCAÇÃO. Educação pública de qualidade: quanto custa esse direito?. São Paulo, 2010.

CARREIRA, Denise; PINTO, José Marcelino Rezende. Custo Aluno-Qualidade Inicial: rumo à educação pública de qualidade no Brasil. São Paulo: Global/Campanha Nacional pelo Direito à Educação, 2007.

CASTRO, Jorge Abrahão de. Política social e desenvolvimento no Brasil. Economia e Sociedade, Campinas, v. 21, dez. 2012. Número Especial. Disponível em: <http://www.scielo.br/scielo.php?script=sci_arttext\&pid=S0104-06182012000400012\&Ing =en\&nrm=iso>. Acesso em: 01 abr. 2017.

CRUZ, Rosana Evangelista da. Pacto federativo e financiamento da educação: a função supletiva e redistributiva da União - o FNDE em destaque. Tese (Doutorado em Educação) Faculdade de Educação, Universidade de São Paulo, São Paulo, 2009.

D’ABADIA, Bruno Magalhães. A Problemática Das Transferências Voluntárias. Brasília, DF.: Câmara dos Deputados, Consultoria Legislativa, maio, 2015.

DI PIETRO, Maria Sylvia Zanella. Parcerias na Administração Pública: concessão, permissão, franquia, terceirização, parceria público-privada e outras. 5 ed. São Paulo: Ed. Atlas, 2005. 
A Educação Pública e as Corporações

DOMICIANO, Cassia Alessandra. A cogestão dos Centros de Educação Infantil "Navemãe": uma parceria público-privada analisada. 2016. 226 f. Tese (Doutorado em Educação) - Faculdade de Educação, Universidade Estadual de Campinas, Campinas, 2016.

FOUNDATION CENTER E GIFE. Key facts sobre o investimento social no Brasil. 2014. Disponível em: <http://keyfacts.censo2014.gife.org.br/>. Acesso em: 19 abr. 2017.

FRANCO, Dalva de Souza. As Creches na Educação Paulistana: 2002 a 2012. Tese (Doutorado em Educação) - Faculdade de Educação, Universidade Estadual de Campinas, Campinas, 2015.

FREITAS, Luiz Carlos de. Os reformadores empresariais da educação e a disputa pelo controle do processo pedagógico na escola. Educação e Sociedade, Campinas, v. 35, n. 129, p. 1085-1114, Campinas, dez. 2014.

GALZERANO, Luciana S. Grupos empresarias e educação básica: estudo sobre a Somos Educação. 2016. Dissertação (Mestrado em Educação) - Faculdade de Educação, Universidade Estadual de Campinas, Campinas, 2016.

GARCIA, Teise et al. O Programa Gestão Nota 10 do Instituto Ayrton Sena na Rede municipal de ensino de São José do Rio Preto: consequências para a gestão educacional. Revista da Faculdade de Educação, Cuiabá, Universidade Do Estado De Mato Grosso, v. 18, p. 123142, 2012.

HILL, Dave. O Neoliberalismo Global, a resistência e a deformação da educação. Currículo sem Fronteiras, Porto Alegre, v. 3, n. 2, p. 24-59, jul./dez. 2003.

HYPOLITO, Álvaro M.; GANDIN, Luís A. Políticas de responsabilização, gerencialismo e currículo: uma breve apresentação. Revista e-Curriculum, São Paulo, n. 11, v. 2, ago. 2013. Disponível em: <http://revistas.pucsp.br/index.php/curriculum/article/viewFile/16610/12461>. Acesso em: 05 dez. 2017.

INVESTIMENTO social corporativo no Brasil em 2014 foi de R $\$ 3,88$ bilhões. GIFE, São Paulo, 2016. Disponível em: <http://gife.org.br/investimento-social-corporativo-em-2014-foi-de-r-388bilhoes/>. Acesso em: 21 abr. 2017.

KISSLER, Léo; HEIDEMANN, Francisco G.. Governança pública: novo modelo regulatório para as relações entre Estado, mercado e sociedade?. Revista de Administração Pública [online], Rio de Janeiro, v. 40, n. 3, p. 479-499, 2006. Disponível em: $<$ http://www.scielo.br/scielo.php?script=sci_arttext\&pid=S0034-76122006000300008\&lng =en\&nrm=iso>. Acesso em: 08 dez. 2017.

KLEES, Steven et al. The World Bank and Education: critiques and alternatives. Roterdam/Boston/ Taipei: Sense Publishers, 2012.

MACIEL, Willians Kaizer dos Santos. Metodologia para o cálculo do indicador "Investimento Público em Educação em relação ao PIB". Brasília: Instituto Nacional de Estudos e Pesquisas Educacionais Anísio Teixeira, 2009. 28 p. il. (Série Documental. Textos para Discussão; 34).

MELCHIOR, José Carlos de Araújo. O Financiamento da Educação no Brasil. São Paulo: EPU, 1987. 
A Educação Pública e as Corporações

MENDES, Marcos J. A Despesa Federal em Educação: 2004-2014. Brasília: Núcleo de Estudos e Pesquisas/CONLEG/Senado, abril/2015. Disponível em: <www.senado.leg.br/ estudos>. Acesso em: 08 dez. 2017. (Boletim Legislativo $n^{\circ} 26$, de 2015).

MOUTINHO, José da Assunção. Transferências voluntárias da União para municípios brasileiros: mapeamento do cenário nacional. Revista de Administração Pública, Rio de Janeiro, v. 50, n. 1, p. 151-166, jan./fev. 2016.

OECD netFWD. Venture Philanthropy in Development: Dynamics, Challenges and Lessons in the Search for Greater Impact. Paris: OECD Development Centre, 2014.

OLIVEIRA, Romualdo Portela de. Direito à educação. In: OLIVEIRA, Romualdo Portela de; ADRIÃO, Theresa. Gestão, Financiamento e Direito à Educação. 3 ed. São Paulo: Xamã, 2007.

PERONI, Vera; ADRIÃO, Theresa. Público não-estatal: estratégias para o setor educacional brasileiro. In: ADRIÃO, Theresa; PERONI, Vera (Org.). O Público e o Privado na Educação: interfaces entre o Estado e Sociedade. São Paulo: Xamã, 2005. p. 138-153.

PINTO, José Marcelino de Rezende. A política recente de fundos para o financiamento da educação e seus efeitos no pacto federativo. Educação e Sociedade, Campinas, v. 28, n. 100, out. 2007.

PINTO, José Marcelino de Rezende; AMARAL, Nelson Cardoso; ABRAHÃO, Jorge. O financiamento do ensino médio no Brasil: de uma escola boa para poucos à massificação barata da rede pública. Educação e Sociedade, Campinas, v. 32, p. 639-665, 2011.

PINTO, José Marcelino de Rezende. Federalismo, descentralização e planejamento da educação: desafios aos municípios. Cadernos de Pesquisa, v. 44, n. 153, p. 624-644, jul./set. 2014. . Disponível em: <http://publicacoes.fcc.org.br/ojs/index.php/cp/article/view/ 2946/2795>. Acesso em: 01 dez. 2017.

REZENDE, Fernando; OLIVEIRA, Fabrício; ARAÚJO Erika (Org.). O Dilema Fiscal: remendar ou reformar?. Rio de janeiro: Editora FGV, 2008.

ROBERTSON, Susan; VERGER, Antoni. A origem das parcerias público-privada na governança global da educação. Educação e Sociedade, Campinas, v. 33, n. 121, p. 11331156, out-dez. 2012.

SENA, Paulo. Reforma tributária e impactos no financiamento da educação. In: BARBOSA, Andréa; PINTO, José Marcelino de Rezende; CORBUCCI, Paulo Roberto (Org.). Federalismo e Políticas Educacionais na Efetivação do Direito à Educação no Brasil. Brasília: IPEA, 2011. 227 p.

SILVA, Luiz Inácio Lula da. Carta ao Povo Brasileiro. 2002. Disponível em: <http://www.fpabramo.org.br/uploads/cartaaopovobrasileiro.pdf>. Acesso em: 08 dez. 2017.

XIMENES, Salomão Barros. Padrão de Qualidade do Ensino: desafios institucionais e bases para a construção de uma teoria jurídica. $424 \mathrm{f}$. Tese (Doutorado em Direito do Estado) - Universidade de São Paulo, São Paulo. 2014. 
A Educacão Pública e as Corporações

Theresa Adrião possui graduação em pedagogia pela Universidade de São Paulo (USP), mestrado e doutorado em Educação pela USP. Atualmente é professora Livre Docente da Faculdade de Educação da Universide Estadual de Campinas (UNICAMP).

E-mail: theadrião@gmail.com

Cassia Alessandra Domiciano é graduada em Pedagogia pela Universidade Estadual Paulista 'Júlio de Mesquita Filho' (Unesp-RC) e mestra em educação pela mesma universidade. Doutora em Educação pela Universidade Estadual de Campinas (UNICAMP). Professora Auxiliar I no Programa de Pós-Graduação em Educação da Universidade Metodista de São Paulo (UMESP).

E-mail: cassiale@uol.com.br 


\title{
Editores do volume 8
}

José Marcelino de Rezende Pinto - Universidade de São Paulo, São Paulo/SP, Brasil

Nalú Farenzena - Universidade Federal do Rio Grande do Sul, Porto Alegre/RS, Brasil

\section{Comitê Editorial}

José Marcelino de Rezende Pinto - Universidade de São Paulo, Brasil

Juca Gil - Universidade Federal do Rio Grande do Sul, Brasil

Theresa Adrião - Universidade Estadual de Campinas, Brasil Ângelo

Ricardo de Souza - Universidade Federal do Paraná, Brasil

Márcia Aparecida Jacomini - Universidade Federal de São Paulo, Brasil

\section{Conselho Editorial}

\section{Alejandro Morduchowicz}

Universidad Pedagógica, Provincia de Buenos Aires, Argentina

Fernanda Saforcada

Universidade de Buenos Aires, Argentina

Jacques Velloso

Universidade de Brasília, Brasil

João Monlevade

Senado Federal, Brasil

Jorge Abrahão de Castro

Instituto de Pesquisa Econômica Aplicada / IPEA, Brasil

Juca Gil

Universidade Federal do Rio Grande do Sul, Brasil

Lisete Regina Gomes Arelaro

Universidade de São Paulo, Brasil

Luis Carlos Sales

Universidade Federal do Piauí, Brasil

Luiz de Sousa Junior

Universidade Federal da Paraíba, Brasil

Luiz Fernandes Dourado

Universidade Federal de Goiás, Brasil

Magna França

Universidade Federal do Rio Grande do Norte, Brasil

\section{Maria Beatriz Luce}

Universidade Federal do Pampa, Brasil

Universidade Federal do Rio Grande do Sul, Brasil

Marcos Edgar Bassi

Universidade Federal do Paraná, Brasil

\author{
Maria Dilnéia Espíndola Fernandes \\ Universidade Federal de Mato Grosso do Sul, Brasil \\ Nalú Farenzena \\ Universidade Federal do Rio Grande do Sul, Brasil \\ Nelson Cardoso do Amaral \\ Universidade Federal de Goiás, Brasil \\ Nicholas Davies \\ Universidade Federal Fluminense, Brasil \\ Rosana Evangelista Cruz \\ Universidade Federal do Piauí, Brasil \\ Rosana Gemaque \\ Universidade Federal do Pará, Brasil \\ Robert E. Verhine \\ Universidade Federal da Bahia, Brasil \\ Romualdo Portela de Oliveira \\ Universidade de São Paulo, Brasil \\ Theresa Adrião \\ Universidade Estadual de Campinas, Brasil \\ Tristan McCowan \\ University of London, Reino Unido \\ Vera Jacob \\ Universidade Federal do Pará, Brasil \\ Vera Peroni \\ Universidade Federal do Rio Grande do Sul, Brasil \\ Vitor Henrique Paro \\ Universidade de São Paulo, Brasil
}

\section{Equipe editorial}

Apoio ao Comitê Editorial: Patrícia Balthazar Garcia

Diagramação, Revisão de português e normalização: Edson Leonel de Oliveira

Revisão de inglês: Ananyr Porto Fajardo 